\title{
Original
}

\section{Motivos de consulta de los inmigrantes en el primer nivel de atención de la CCSS, Distrito Primero del Cantón Central de Alajuela durante 2002}

Manrique Leal-Mateos', Ricardo Salazar-Solís², Javier Ruiz-Castro ${ }^{3}$

Re sum e n

' Médico Director, Área Rectora de Salud de Alajuela 2

2 Médico Asistente Encargado de Vigilancia Epidemiológica, Área Rectora de Salud de Alajuela 2

${ }^{3}$ Médico Asistente Encargado de Regulación de los Servicios de Salud, Área Rectora de Salud de Alajuela 2
Abreviaturas: CCSS; Caja Costarricense de Seguro Social; EBAIS; Equipo básico de atención integral en salud; OPS, organización panamericana de la salud.

Correspondencia: Manrique Leal Mateos, Apartado 55 Centro Comercial San José 2000. Facsímil: 296-340I.
Objetivo: Describir los motivos de consulta de los inmigrantes que asistieron a los servicios de salud del primer nivel de atención del distrito primero del cantón Central de Alajuela pertenecientes al área de salud de Alajuela Norte, durante 2002.

Métodos: Se trata de un estudio descriptivo de corte transversal. Se recogieron las siguientes variables: edad, sexo, nacionalidad, sede de EBAIS donde que se consultó y motivo de la consulta.

Resultados: Se registraron 1076 consultas de inmigrantes, correspondientes a 467 personas extranjeras.

Del total de consultas, $853(79.3 \%)$ se otorgaron a mujeres. El promedio por paciente fué de 2.3 consultas y la edad media, de 39.8 años.

Respecto a la nacionalidad, $772(71.7 \%)$ consultas se realizaron a pacientes nicaragüenses, 140 (13\%) colombianos y 41 (3.8\%) salvadoreños.

Los tres diagnósticos o motivos de consulta que mayor demanda de servicios de salud registraron fueron: control de patología o exámenes de laboratorio, infecciones de vías respiratorias superiores e infecciones del tracto urinario.

El EBAIS que atendió a más inmigrantes fue Cristo Rey con 241 consultas $(22,4 \%)$.

Conclusiones: Los pacientes inmigrantes que asisten a los servicios de salud del primer nivel de atención del Distrito Primero del Cantón Central de Alajuela pertenecientes al Área de Salud de Alajuela Norte, durante 2002, son jóvenes, predominantemente de sexo femenino.

Descriptores: motivos de consulta, inmigrantes, primer nivel atención, Alajuela.

Recibido: 05 de agosto de 2003 
Una de las características poblacionales de la que menos información se tiene en el mundo es la inmigración internacional, por ello, las estimaciones disponibles de los movimientos internacionales de personas pueden diferir considerablemente de la realidad.

Según el informe La salud en las Américas edición 1998 de la OPS, “...Estados Unidos es el país que recibe el mayor número de inmigrantes del mundo y este flujo es significativamente mayor a cualquier otro país en América Latina... Sin embargo, la población inmigrante constituye una proporción relativamente equivalente en cada país; es decir que esta carga de inmigración es proporcional al tamaño de la población del país receptor...". ${ }^{1}$

Las cifras de inmigrantes regularizados en Europa Occidental se sitúa en torno a 20 millones de personas y esto no ha hecho más que empeorar en vista del fuerte aumento de la población mundial y del estado de subdesarrollo y pobreza en que se encuentran gran parte de los países de América y África. Además, se da la singularidad de una Europa envejecida y deseosa de personas jóvenes que puedan seguir con el ritmo de progreso y desarrollo creado en los últimos años. ${ }^{2}$

Los problemas económicos observados en muchos países de Latinoamérica hacen que algunos de sus habitantes se vean obligados a abandonar su país con la esperanza de mejorar su calidad de vida. Es posible afirmar que la salud de los inmigrantes se vea afectada por situaciones de marginación, hacinamiento y pobreza. Las grandes desigualdades sociales, económicas y de salud en que la mayoría de ellos viven, contribuyen al deterioro de su nivel de vida. ${ }^{3-5}$

Diferentes autores resaltan la mayor parte de las consultas atendidas a pacientes extranjeros son fundamentalmente por problemas muy relacionados con su situación económica y social. Los trastornos depresivos se colocan como la segunda causa de consulta en esta población, seguida de los síntomas inespecíficos, cuyo componente psicológico tiene una expresión clara. Además, relacionan ciertas patologías, como las lumbalgias, con trabajos de escasa o nula protección, producto de las condiciones laborales en que muchos se ven obligados a trabajar. ${ }^{6-8}$

Desde hace algunos años Costa Rica se ha convertido en un país receptor de inmigrantes de Centro y Suramérica, lo que ha propiciado una nueva realidad sanitaria escasamente reconocida por las instituciones del gobierno, que supone un nuevo reto para los profesionales de la salud. ${ }^{9-12}$

En Costa Rica existen trabajos de investigación dirigidos al estudio de las condiciones de vida y las características demográficas de los inmigrantes, pero pocos son los trabajos orientados a explorar los padecimientos que los aquejan, o los principales motivos de consulta por los que asisten a los servicios de salud de la CCSS. ${ }^{13-15}$ Aunque muchos autores, tanto nacionales como extranjeros, afirman que no representan una amenaza como importadores de enfermedades, se puede concluir que su forma de vida o trabajo representa un riesgo importante para la salud pública del país ${ }^{3}$. Las condiciones en que conviven es un factor determinante para el desarrollo de enfermedades que hasta el momento se consideraban controladas o ajenas al perfil epidemiológico de la salud nacional. ${ }^{16}$

El desconocimiento de las autoridades de salud sobre los principales padecimientos de este grupo, fomenta una percepción negativa de los inmigrantes. Fenómeno que puede influir en su recepción e integración a los servicios sociales y de salud y contribuir a su marginación. ${ }^{16}$

El estudio propone dar a conocer el estado de salud de la población inmigrante que asiste a los servicios de salud del primer nivel de atención de la CCSS, en el distrito primero del cantón Central de Alajuela, pertenecientes al área de salud de Alajuela Norte, para facilitar la puesta en marcha de programas y estrategias de Salud Pública. Pretende, además, conocer sobre las características diferenciales y las enfermedades más comunes en ellos con el fin de relacionarlas con las de la población costarricense y verificar si difieren o no.

Una de las principales limitaciones del estudio es que no se pudo contar con el total de la población inmigrante del distrito primero del cantón central de Alajuela, debido la movilidad geográfica que los caracteriza y a que muchos de los inmigrantes que se encuentran en situación ilegal en Costa Rica, no acuden a los servicios de salud; los que si lo hacen, en ocasiones señalan nombres o direcciones inciertas, por el temor a ser reportados y extraditados.

\section{Materiales y métodos}

De acuerdo con el objetivo planteado en la investigación, esta es de tipo descriptivo de corte transversal.

La investigación la componen las consultas de pacientes extranjeros de diferentes nacionalidades, que utilizaron los servicios de salud del primer nivel de atención de la CCSS en el distrito primero del cantón central de Alajuela y que pertenecen al área de salud de Alajuela Norte, durante el período comprendido entre el 1 de enero de 2002 y el 31 diciembre de 2002.

Se utilizaron como fuente de información, los expedientes clínicos de cada paciente, localizados mediante la revisión de las agendas diarias de la consulta externa de los EBAIS de la zona.

De los expedientes encontrados, se escogieron aquellos de los pacientes extranjeros que cumplieron con los siguientes criterios: Edad mayor a 15 años, empleo de la consulta de morbilidad por demanda y residencia en el distrito primero del cantón central de Alajuela. 
Posteriormente se revisó cada expediente clínico para obtener la edad, el sexo, la nacionalidad, la sede de EBAIS que registró la consulta realizada y el motivo de esta.

Para fines del estudio, se entendió por "motivo de consulta", la impresión diagnóstica registrada por el médico tratante en el expediente clínico de cada paciente.

Luego, con base en la misma metodología, se escogió de forma sistemática y aleatoria, tres expedientes de pacientes con nacionalidad costarricense que cumplieron con las mismas características, los cuales fueron utilizados como referencia al de comparar las variables de estudio.

Por último, se clasificó cada diagnóstico dentro de las categorías de enfermedades o problemas relacionados con la salud, según la clasificación internacional de las enfermedades en su décima versión CIE-10.

Por ser el propósito fundamental del estudio determinar los principales motivos de consulta de la población inmigrante, no se incluyeron aquellas de un mismo paciente en las cuales el diagnóstico registrado resultó ser igual al de alguna consulta anterior.

Asimismo, no se tomó en cuenta a aquellos pacientes a los que fue imposible localizarles el expediente, aunque aparecieran registradas sus consultas en la agenda diaria de cada EBAIS.

El registro básico se efectuó en un formulario elaborado con preguntas abiertas y cerradas, precodificadas, para luego ser incluídas en una base de datos informatizada. Se utilizó el programa EpiInfo 2000 para el procesamiento de los datos. Se emplearon técnicas estadísticas descriptivas.

\section{Resultados}

De enero a diciembre de 2002, se localizaron en las agendas diarias de la consulta externa de los EBAIS, 503 pacientes inmigrantes que cumplían con los criterios de inclusión. De estos, 13 se excluyeron debido a que no fue posible localizar su expediente y 23 más por no poder determinar su nacionalidad con exactitud.

Por tanto, se utilizó una muestra no probabilística de 467 expedientes de personas extranjeras, para un registro de 1076 consultas atendidas.

Del total de consultas, $853(79.3 \%)$ se otorgaron a mujeres y $223(20.7 \%)$ a hombres. La media de consultas por paciente corresponde a 2.3 la edad media fue de 39.8 años.

Respecto a la nacionalidad, 772 (71.7\%) consultas se realizaron a pacientes nicaragüenses, 140 (13\%) a colombianos y 41 (3.8\%) salvadoreños. Las nacionalidades del total de los pacientes se muestran en el cuadro 1.

\begin{tabular}{|c|c|c|}
\hline \multicolumn{3}{|c|}{$\begin{array}{l}\text { Cuadro 1: Número de consultas a pacien- } \\
\text { tes inmigrantes según país de origen. } \\
\text { Distrito Primero del Cantón Central de Alajuela, } \\
\text { Área de Salud de Alajuela Norte, } 2002 \\
\text { (Cifras absolutas y relativas) }\end{array}$} \\
\hline País de origen & Número de consultas & Porcentaje \\
\hline Alemania & 2 & 0.2 \\
\hline Colombia & 140 & 13 \\
\hline Cuba & 25 & 2.3 \\
\hline EEUU & 7 & 0.7 \\
\hline Filipinas & 1 & 0.1 \\
\hline Guatemala & 7 & 0.7 \\
\hline Holanda & 3 & 0.3 \\
\hline Honduras & 4 & 0.4 \\
\hline Indonesia & 2 & 0.2 \\
\hline Italia & 2 & 0.2 \\
\hline Japón & 1 & 0.1 \\
\hline México & 2 & 0.2 \\
\hline Nicaragua & 772 & 71.7 \\
\hline Panamá & 22 & 2.0 \\
\hline Perú & 29 & 2.7 \\
\hline Rep. Dominicana & 11 & 1.0 \\
\hline El Salvador & 41 & 3.8 \\
\hline Uruguay & 1 & 0.1 \\
\hline Venezuela & 2 & 0.2 \\
\hline Vietnam & 2 & 0.2 \\
\hline Total & 1076 & 100 \\
\hline
\end{tabular}

Según el CIE-10, las categorías por enfermedad o problemas relacionados con la salud que mayor número de consultas registraron fueron: factores que influyen en el estado de salud, y contacto con los servicios de salud con 175 consultas (16.3\%), enfermedades del aparato respiratorio con 122 consultas $(11.3 \%)$ y las enfermedades del aparato genitourinario con $122(11.3 \%)$.

Los tres diagnósticos o motivos de consulta que mayor demanda de servicios de salud registraron fueron: control de de patología o exámenes de laboratorio, con 63 consultas; infecciones de vías respiratorias superiores, con 60 consultas e infecciones del tracto urinario con 57 (figura $\mathrm{N}^{\circ} 1$ ).

El EBAIS que atendió a más inmigrantes fue Cristo Rey con 241 consultas $(22,4 \%)$ (figura $\mathrm{N}^{\circ} 2$ ).

Se seleccionaron 1329 pacientes costarricenses como controles. Las consultas atendidas para este grupo fueron 1554. El promedio por paciente fue de 1.2 consultas. Del total de citas registradas, $1106(71.2 \%)$ se realizaron a mujeres y 448 (28.8\%) a hombres. La media de edad fue de 48.8 años.

Las categorías por enfermedades o problemas relacionados con la salud que mayor número de consultas registraron fueron: factores que influyen en el estado de salud, y contacto con los servicios de salud con 290 consultas (18.7\%); enfermedades del sistema circulatorio, con 193 consultas (12.4\%), y enfermedades del sistema respiratorio, con 171 (11\%). 


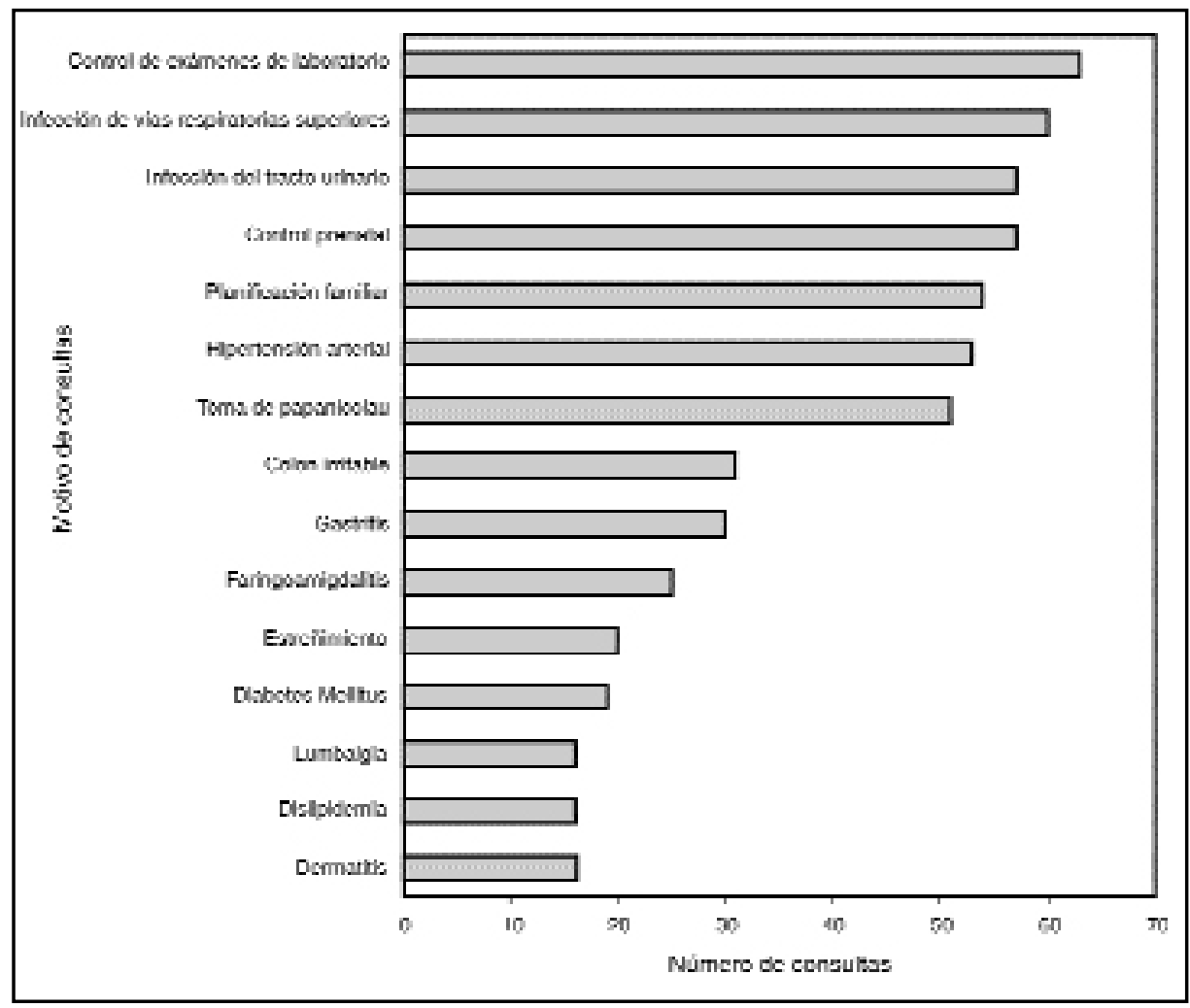

Figura 1. Número de consultas de pacientes inmigrantes según los primeros 15 motivos de consulta, Distrito Primero, Cantón Central de Alajuela, Área de Salud de Alajuela Norte, 2002. (Cifras absolutas).

Los tres diagnósticos o motivos de consulta que mayor demanda de servicios de salud registraron son: hipertensión arterial con 168 consultas $(10.8 \%)$, control prenatal con 118 consultas $(7.6 \%)$ y diabetes mellitus con 107 consultas (6.9\%) (figura 3).

\section{D i s c u s ión}

Según los informes del Estado de la Nación y diferentes medios de prensa escrita, Costa Rica ha sido el país que cuenta con mayor número de inmigrantes. La mayoría de los extranjeros que residen en la nación son de países de Centro y Suramérica. Si bien se conoce acerca del proceso migratorio como tal, hay pocos datos sobre el estado de salud de esta población. ${ }^{9-12}$

En el estudio se pudo observar que la población extranjera que utiliza los servicios de salud del primer nivel de atención de la CCSS en el distrito primero del cantón central de Alajuela, pertenecientes al Área de Salud de Alajuela Norte, es relativamente joven. Lo anterior coincide con varios autores que mencionan que la población inmigrante es joven y en general con buen estado de salud. 2,3,5 También se concuerda con lo expresado en el informe 4 del Estado de la Nación, donde se menciona que los inmigrantes se concentran en el grupo de edad de 15 a 44 años.
Por las características del estudio y por la muestra escogida, no es posible generalizar los datos a toda la población inmigrante del país, en la provincia, e inclusive en el distrito, por lo que nos limitaremos a describir los motivos de consulta de la población que asistió a los servicios del primer nivel de atención de la CCSS, durante 2002.

Otra de las limitaciones encontradas es la escasa bibliografía existente sobre el tema en el país. Las publicaciones utilizadas en esta investigación pertenecen a estudios realizados en otras naciones, y en su mayoría en Europa, lo que dificulta la comparación de los resultados obtenidos en el presente trabajo.

Se pudo determinar que existe una mayor demanda de los servicios de salud por parte de las mujeres inmigrantes, comportamiento observado para la población local del distrito. Lo anterior se podría relacionar con lo expuesto en el informe 5 del Estado de la Nación, donde se indica que el proceso migratorio ha sufrido una "feminización" en los últimos años. Además, este mismo informe menciona como en el área urbana existe un mayor predominio del sexo femenino sobre el masculino, situación inversa a la del área rural.

Según el informe 5 del Estado de la Nación, para 1997 las personas nacidas en Nicaragua representaban el $73 \%$ de la población inmigrante. Esto puede verse reflejado también en las consultas atendidas por los servicios de salud del distrito, donde el $71.7 \%$ fueron concedidas a población de esa nacionalidad.

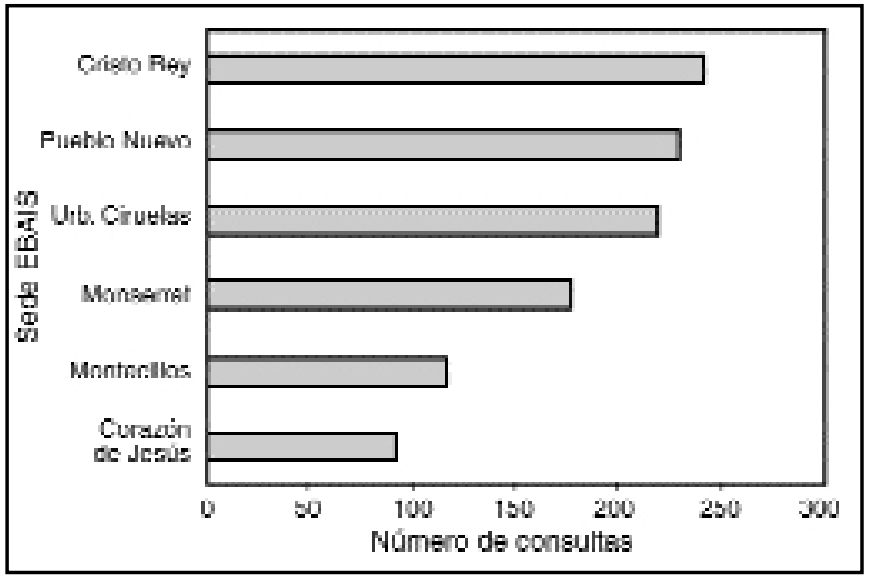

Figura 2. Número de consultas de pacientes inmigrantes según, sede de EBAIS, Distrito Primero, Cantón Central de Alajuela, Área de Salud de Alajuela Norte, 2002. (Cifras absolutas). 


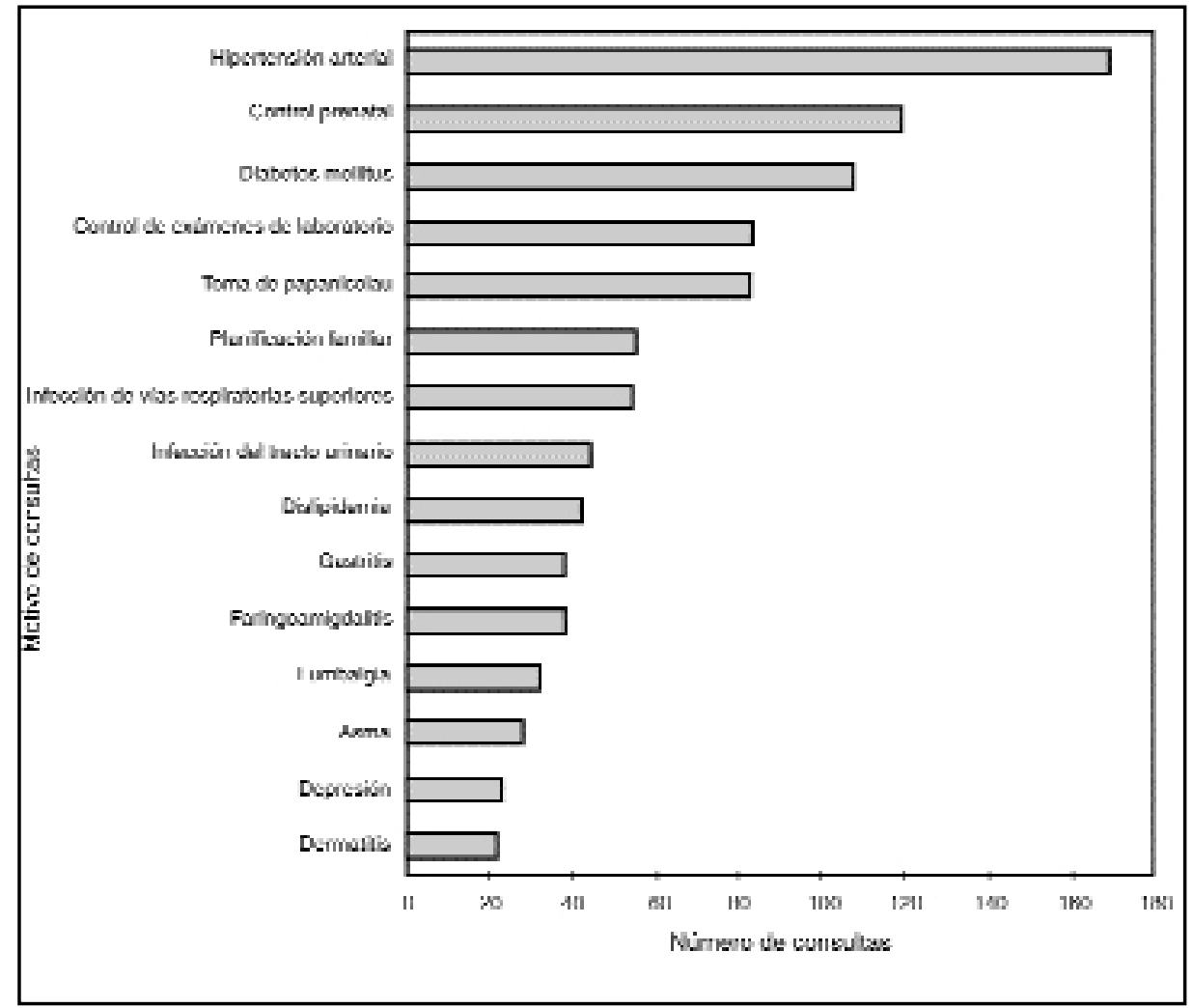

Figura 3. Número de consultas, según los primeros 15 motivos de consulta de las población costarricense, distrito primero, cantón central de Alajuela, Área de Salud de Alajuela Norte, 2002. (Cifras absolutas).

Se observó que al tomar como muestra los primeros 15 motivos de consulta para ambas poblaciones, doce de ellos son comunes para ambos grupos, lo que demuestra que las enfermedades diagnosticadas en los inmigrantes son semejantes a las de la población local.

Para la población inmigrante, se puede notar que dentro el grupo de ciertas enfermedades infecciosas y parasitarias, las patologías que mayor número de diagnósticos registraron fueron las infecciones de vías respiratorias superiores, así como las de tracto urinario. Lo anterior apoya la teoría de que la población inmigrante no trae consigo enfermedades emergentes o reemergentes que en algún momento se consideraron erradicadas del país; por el contrario, toma fuerza la hipótesis de que esta población padece enfermedades propias de la zona donde reside. ${ }^{6,7}$

La migración es, junto a la mortalidad y fecundidad, la tercera variable condicionante de los cambios demográficos. La búsqueda de mejores condiciones de vida ha sido uno de los principales motivos para la migración. ${ }^{4}$

Alrededor de la mitad de los movimientos migratorios internacionales se producen de un país en desarrollo a otro, por lo general geográficamente cercanos y culturalmente relacionados. ${ }^{5}$
Desde hace algunos años, Costa Rica se ha convertido en un país receptor de inmigrantes. La estabilidad política y la baja tasa de desempleo han hecho que sea el destino de muchos inmigrantes de Centro y Suramérica. 12, 13, 14, 15

El último informe elaborado por la Organización Panamericana de la Salud manifiesta que las autoridades de nuestro país han abordado el problema migratorio exclusivamente desde una perspectiva económica y de sus efectos sobre los servicios públicos de salud, fomentando una percepción negativa de la inmigración. ${ }^{16}$

El perfil de salud de la población estudiada es semejante, al de la población costarricense que asiste a los servicios de atención del mismo distrito de residencia.

De las conclusiones obtenidas en este estudio se recomienda:

Definir políticas que eviten el sentimiento de rechazo por parte de la población local; por el contrario, se debe fomentar la integración de ellos a los programas preventivos de los servicios de salud del país.

Abordar a los inmigrantes desde una perspectiva multidisciplinaria, flexible y activa, que mejore la comunicación entre ellos y los profesionales de salud, para reforzar las actividades preventivas y de promoción.

Insistir en ejecutar investigaciones para conocer la situación real de este grupo y así no responsabilizar directamente a los inmigrantes de los cambios epidemiológicos que ha sufrido el país en los últimos años.

\section{A b stract}

Objective: To describe the reasons of consultation of immigrants who attended the health services at the first attention level at the First District of the Central Canton of Alajuela that belongs to "Area de Salud Alajuela Norte", during 2002.

Methods: This is a cross-sectional descriptive study. The following variables were collected: age, gender, nationality, consult place reason of consultation.

Results: A total of 467 foreigners consulted 1076 times. 
Among all consults, 853 (79.3\%) were made by women and $223(20.7 \%)$ by men. The average of the consults was 2.3 consults per patient. The median age was 39.8 years old.

Regarding nationality, 772 (71.7\%) consults were made by nicaraguan patients, 140 (13\%) by colombian patients and $41(3.8 \%)$ by salvadorans.

The main reasons for consultation were testing control of an existing disease process or for laboratory testing, upper respiratory infections and urinary tract infections.

The place where most immigrants consulted was the EBAIS form Cristo Rey with 241 (22.4\%) consultations.

Conclusion: The immigrant patients who attend first level health services of attention are young people, principally females and with diseases similar to the Costa Rican population from the same district.

\section{Referencias}

1. Organización Panamericana de la Salud. Volumen 1: La Salud en las Américas, Edición de 1998. Washington D.C.: OPS, 1990.

2. M. M Esteban y Peña. Motivos de consulta de una comunidad de inmigrantes "sin papeles" en el distrito de Usera-Villaverde (Madrid). Aten Primaria 2001; 27: 25-28.

3. Vidal J., Jansá J.M., López .V et al. Enfermedades infecciosas y características sociodemográficas de los inmigrantes extranjeros del Centro Penitenciario de Hombres de Barcelona. Rev Esp Salud Pública 1998; 75:197-208.

4. Gutiérrez M. Trastornos en minorías étnicas: ¿un tema para investigar en atención primaria?. Aten Primaria 2002; 29: 12-13.

5. Jansá J.M. y Villalbí J.R. . La salud de los inmigrantes y la atención primaria. Aten. Primaria 1995; 15: 320-326.

6. Balanzó X. . Enfermedades importadas y medicina de la inmigración. Aten. Primaria 1991; 8: 527-528.

7. Martín Laso M. El paciente inmigrante en atención primaria ¿Estamos preparados? . Aten Primaria 2001; 28: 89-90

8. Francisco A. La globalización de la Salud: entre el reduccionismo económico y la solidaridad ciudadana. Revista Facultad Nacional de Salud Pública 2001; 19: 44-55

9. Proyecto Estado de la Nación en Desarrollo Humano Sostenible. Estado de la Nación en desarrollo sostenible: Cuarto informe. San José, Costa Rica: Proyecto Estado de la Nación, 1997.

10. Proyecto Estado de la Nación en Desarrollo Humano Sostenible. Estado de la Nación en desarrollo sostenible: Quinto informe. San José, Costa Rica: Proyecto Estado de la Nación, 1998.

11. Proyecto Estado de la Nación en Desarrollo Humano Sostenible. Estado de la Nación en desarrollo sostenible: Octavo informe. San José, Costa Rica: Proyecto Estado de la Nación, 2001.

12. Soza, $\mathrm{C}$ y Naudon, M. Inmigrantes latinos buscan nuevos horizontes. La Nación 2003, miércoles 30 de abril; sección "Economía": 27-A

13. Brenes, G. Estimación del volumen y características sociodemográficas de los inmigrantes nicaragüenses en Costa Rica. Tesis, Universidad de Costa Rica, Ciudad Universitaria Rodrigo Facio: San Pedro de Montes de Oca, 1998.

14. Castro C. y Morales A. La inserción laboral de la fuerza de trabajo nicaragüense en el sector de la construcción, la producción bananera y servicio doméstico en Costa Rica, San José, Costa Rica: FLACSO, 1998.

15. García A. y Guzmán G. Estudio de las condiciones de vida de los inmigrantes nicaragüenses en las fincas bananeras para orientar las políticas de salud. Tesis, Universidad de Costa Rica, Ciudad Universitaria Rodrigo Facio: San Pedro de Montes de Oca, 1998.

16. Organización Panamericana de la Salud. Migración y salud en Costa Rica: Elementos para su análisis. San José, Costa Rica: OPS, 2003. 